\title{
Assessment of Risk of Misinforming: Dynamic Measures
}

\author{
Dimitar Christozov \\ American University in Bulgaria, Blagoevgrad, Bulgaria \\ dgc@aubg.bg \\ Stefanka Chukova \\ Victoria University of Wellington, Wellington, New Zealand \\ stefanka@vuw.ac.nz \\ Plamen Mateev \\ Sofia University "St. Kliment Ohridski”, Sofia, Bulgaria \\ pmat@fmi.uni-sofia.bg
}

\begin{abstract}
This paper addresses the impact of warranty of malfunctioning and warranty of misinforming on making informed purchase decisions over the adoption period. We propose mathematical models for quantification of the risk of misinforming by exploring customers' learning evolution. These measures, dynamic in their nature, allow evaluation of customer's satisfaction or dissatisfaction as a function of the misinforming warranty coverage over learning time.
\end{abstract}

Keywords. Risk, Misinforming, Learning, Warranty

\section{Introduction}

This paper advances the research on warranty of misinforming by extending the models developed by Christozov, Chukova, and Mateev (2009b). It addresses the evolution of the risk of a wrong purchase decision over the period of adoption of a new product and the role of warranty in this process. Let us assume that a customer purchases a new product, e.g., a new personal computer (PC). The purchase in made in order to address some particular needs and solve a particular set of customer's tasks, e.g., to develop text documents, to make simple or complex calculations, to send and receive e-mails, for Internet browsing, to play games, or to listen music and watch movies. The PC has particular characteristics (specification), such as CPU speed, memory capac-

Material published as part of this publication, either on-line or in print, is copyrighted by the Informing Science Institute. Permission to make digital or paper copy of part or all of these works for personal or classroom use is granted without fee provided that the copies are not made or distributed for profit or commercial advantage AND that copies 1) bear this notice in full and 2) give the full citation on the first page. It is permissible to abstract these works so long as credit is given. To copy in all other cases or to republish or to post on a server or to redistribute to lists requires specific permission and payment of a fee. Contact Publisher@InformingScience.org to request redistribution permission. ity, etc., which allow the customer to solve her tasks. There are two stages in the adoption (acceptance) of a new product. The first one is making the purchase decision. The second one is related to the initial period of product usage when the buyer discovers whether the product meets her needs. The product warranty, offered by the producer, could provide coverage for two issues that the buyer may encounter. The first 
one is related to the malfunctioning of the product, i.e., the product does not function according to its specifications. In this case, the product is repaired or replaced with no charge to the customer. The second issue is related to buyer's satisfaction, i.e., to what extend the product meets the buyer's needs to solve for her tasks. In other words, to what extent, at the time of the purchase, the customer has been misinformed regarding the product's ability to solve her tasks and to satisfy her needs. The warranty that provides coverage against the second issue we call "warranty of misinforming". If the customer is not "fully satisfied", the warranty of misinforming allows for the return of the product. The warranty of misinforming provides an opportunity for the client to explore and learn about the properties and features of the product without incurring any risk.

Over the period of learning, the risk that the product will not satisfy the customer's needs evolves as well. On one hand, the customer learns how the product properties relate to her needs, but on the other hand, the client learns what the product can offer, and based on this new information, extends/modifies the set of her tasks and related needs. Modelling the dynamics of this risk is the objective of our paper.

The role of warranty as the product's malfunctioning risk sharing mechanism is well studied. The role of warranty as a promotional tool is also well explored. Models to evaluate the risk of misinforming were introduced by Christozov, Chukova, and Mateev (2007) and further developed in a series of papers $(2008,2009 a, 2009 b, 2009 c, 2010)$. In these papers this risk and its warranty coverage were studied. The role of warranty to support learning was discussed as well. Here we investigate how this learning process influences the risk of misinforming. A brief literature review you can find in Chritozov, Chukova, and Mateev (2009b). The notations and definitions used so far are given in the Appendix.

In the next section we briefly introduce the basic terms and notations used in the models, composition of a warranty policy, and the static measures of the risk of misinforming. The third section addresses the dynamic measures of the risk of misinforming by introducing and exploring the buyer's learning evolution.

\section{The Model - An Overview}

\section{Basic Terms and Notations}

The group of buyers is denoted by $B=\left\{b_{j}\right\}, j=1,2, \ldots, n$, where $b_{j}$ represents the $j^{\text {th }}$ buyer. Each $b_{j}$ has a set of tasks that s/he needs to solve for. Let $A_{j}=\left\{a_{i j}\right\}, i=1,2, \ldots, k_{j}$, be the set of the $k_{j}$ tasks of the $b_{j}$ that s/he needs to solve for by using product D. Assume that for every task $a_{i j}$, the $b_{j}$ has a degree of acceptance of the product with respect to this task, say $q_{i j}$. The degree of acceptance of the product $q_{i j}$ is a measure of the buyer's judgment regarding the minimal quality the product $\boldsymbol{D}$ has to have in order to be suitable to solve for this task. It is described in terms of quality of the product and its value is within $[0,1]$. If any product is acceptable then $q_{i j}=0$, whereas, if $q_{i j}=1$, the buyer has very high expectations on the quality of the product regarding $a_{i j}$. About estimation of $q_{i j}$ from empirical data see Christozov, Chukova, and Mateev (2008). In this study we assume that $q_{i j}$ is known and normalized.

The set of tasks $A=\bigcup_{j=1}^{n} A_{j}$ can be structured according to the tasks that are common for many, not necessarily all, buyers. Each common task specifies a particular category within the set of tasks $A$ (e.g., Internet surfing). Of course, different buyers have different criteria of what is acceptable performance of the product in using tasks in given category. For completeness an assumption is made that all buyers have all tasks, but for some of these tasks the buyer's need to solve for is equal to zero. Let $A_{i}^{*}, i=1,2, \ldots, k$ denote the $i^{t h}$ category of tasks for the set of buyers 
$B$. Note that some of the tasks the buyer needs to solve using the product may not be among the tasks the product is design for. Therefore, the probability that the product is suitable to solve for such tasks is assumed to be equal to zero. Then, $A^{*}=\bigcup_{i=1}^{k} A_{i}^{*}$ is the set of all different tasks and, of course, $A^{*}=A$ Set $A$ describes the set of tasks as a union of buyers' tasks, whereas $A^{*}$ is the same set of task from category point of view.

The need of the $b_{j}$ to solve for a task from category $A_{i}{ }^{*}$ is $n_{i j}$, where $0 \leq n_{i j} \leq 1$. If $n_{i j}=0$, then the $b_{j}$ does not need to solve for any task from $A_{i}{ }^{*}$, whereas, if $n_{i j}=1, b_{j}$ definitely needs to solve for a task from $A_{i}{ }^{*}$. In case of $n_{i j}=0$, then $q_{i j}=0$, i.e., if $b_{j}$ does not need to solve a task from $A_{i}{ }^{*}$, then any product is acceptable for him. The value of $n_{i j}$ is completely subjective. The $b_{j}$ is described by the triple $b_{j}=\left\{\left(a_{i j}, q_{i j}, n_{i j}\right) \mid a_{i j} \in A_{i}{ }^{*}, i=1,2, \ldots, k, 0 \leq n_{i j}, q_{i j} \leq 1\right)$. For each buyer all $a_{i j} \in A^{*}$ are presented in his description, but for some of these tasks the corresponding need may be zero.

The seller sells the product $\boldsymbol{D}$, which is capable of solving tasks from $A_{i}{ }^{*}$. Let $p_{i}=p\left(A_{i}{ }^{*}\right)$ be the probability that $\boldsymbol{D}$ is suitable to solve for a task from $A_{i}{ }^{*}$. If $p\left(A_{i}{ }^{*}\right)=0$, then $\boldsymbol{D}$ is not suitable at all for solving for this category of tasks, whereas, if $p\left(A_{i}^{*}\right)=1, \boldsymbol{D}$ is an excellent choice for solving for tasks from $A_{i}{ }^{*}$, i.e., $\boldsymbol{D}$ meets any level of buyer's degree of acceptance, related to tasks in $A_{i}{ }^{*}$. Further, as a part of his marketing policy, the seller sends a message to a group of buyers describing the properties/qualities/features of $\boldsymbol{D}$. The content of this message is based on the seller's evaluation of $p\left(A_{i}{ }^{*}\right)$ and it does not take into account the value of $\left\{q_{i j}\right\}, j=1,2, \ldots, n$. In this communication, the information asymmetry is due to the difference between the expertise of the seller and the buyer regarding the product $\boldsymbol{D}$. The usage of specific terminology in the message may increase the level of information asymmetry. Based on this message and his/her background, the $b_{j}$ assesses the probability $\hat{p}_{i j}=\hat{p}\left(a_{i j}\right)$ that the product $\boldsymbol{D}$ is suitable to solve for his/her task $a_{i j}$. If $n_{i j}$ $=0$ and $/$ or $q_{i j}=0$, then there is no need to estimate $\hat{p}\left(a_{i j}\right)$.

$b_{j}$ makes his/her purchase decision based on the comparison between $\left\{\hat{p}_{i j}\right\}$ and $\left\{q_{i j}\right\}$ over all tasks from his/her set $A_{j}$. Due to the information asymmetry, the values of $p_{i}$ and $\hat{p}_{i j}$ may differ significantly. Also these values may differ because $p_{i}$ is evaluated by the seller for the category of tasks $A_{i}{ }^{*}$ and not for the particular $a_{i j} \in A_{i}{ }^{*}$, which is of interest to $b_{j}$.

\section{Pure and Mixed Warranty Policies}

The two types of pure warranties, the warranty of malfunctioning $W_{R}\left(t^{R}\right)$ and warranty of misinforming $W_{I}\left(t^{I}\right)$, have one main parameter of interest - their warranty period, $t^{R}$ and $t^{I}$, respectively. During this warranty period ${ }^{1}$, warranty claims against a faulty product are legitimate. A mixed warranty policy $W_{p}=\left\{t^{R}, t^{I}\right\}$ accounts for both types of warranties and it is identified by two ordered time periods, $t^{R}$ and $t^{I}$. During time period of length $t^{R}$ after the product sale all warranty claims against the product performance are legitimate and during $t^{I}$ all warranty claims against the product suitability are legitimate. The mixed warranty combines the warranty of mal-

\footnotetext{
${ }^{1}$ Here, by "time" we mean any measure of the warranty coverage, not necessarily the calendar time. For example, in automobile industry, the warranty coverage is identified not only by the vehicle's age, but accounts also for the accumulated mileage, i.e., "time" could by the age of the vehicle, or it could be the accumulated mileage.
} 
functioning and warranty of misinforming and provides a uniform mechanism for risk sharing for both types of uncertainties - uncertainties related to malfunctioning as well as uncertainties related to misinforming. We call a warranty policy, which covers only one category of risks, pure warranty policy, and a policy that covers both risks - mixed. With $\mu_{i j}, 0 \leq \mu_{i j} \leq 1$, we denote the importance of the warranty of misinforming for client $b_{j}$ with respect to task $a_{i j}$.

The value $B\left(W_{i j}\right)=\mu_{i j} t^{I}+\left(1-\mu_{i j}\right) t^{R}$ represents the "balanced" value of the "warranty parameter" that provides the support for the $b_{j}$ purchase decision with respect to task $a_{i j}$. From client's viewpoint, the "balanced" value $B\left(W_{i j}\right)$ integrates the importance of the two warranty aspects - malfunctioning and misinforming with respect to task $a_{i j}$. Increasing the value of the balanced warranty parameter $B\left(W_{i j}\right)$ increases the quality of the warranty policy for the client $b_{j}$ with respect to task $a_{i j}$. The standard deviation $Q\left(W_{i j}\right)=\sqrt{\left(t^{I}-B\left(W_{i j}\right)\right)^{2} \mu_{i j} .+\left(t^{R}-B\left(W_{i j}\right)\right)^{2} \cdot\left(1-\mu_{i j}\right)}$ measures the "error" from the best "balanced" value of the warranty parameter and represents the uncertainty allowed by the warranty policy in supporting client's $b_{j}$ correct purchase decision with respect to task $a_{i j}$. Decreasing the value of this uncertainty increases the quality of the warranty policy. Therefore, the client $b_{j}$ is described by the tuple $b_{j}=\left\{\left(a_{i j}, q_{i j}, n_{i j}, \mu_{i j}\right) \mid a_{i j} \in A_{i}{ }^{*}, i=1,2, \ldots, k, 0 \leq n_{i j}\right.$, $\left.q_{i j}, \mu_{i j} \leq 1\right)$.

In the proposed dynamic measures for the risk of misinforming we incorporate the measure of importance $\mu_{i j}$ and the ideas of the notion of quality of warranty policy.

From producer's point of view, a mixed warranty policy $W_{p}$ is of high (optimal) quality, if it minimizes the expected warranty servicing cost and it maximizes the level of product acceptance by the clients. From client's point of view, a mixed warranty policy $W_{p}$ is of high (optimal) quality, if the "balanced" value of the "warranty parameter" is maximal and the level of uncertainty it allows in supporting client's correct purchase decision is minimal.

By normalizing $\mu_{i j}$ over all possible $k$ categories of tasks by using $\mu_{i j}^{j}=\frac{\mu_{i j}}{\sum_{i=1}^{k} \mu_{i j}}$ and over all possible $k$ categories of tasks and all clients $\mu_{i j}^{a}=\frac{\mu_{i j}}{\sum^{J} \sum^{k}}$ we obtain the relative measure of impor$\sum_{j=1}^{j} \sum_{i=1}^{k} \mu_{i j}$

tance of misinforming warranty for task $a_{i j}$ for client $b_{j}$.

Based on the quality of the warranty policy for client $b_{j}$ with respect to task $a_{i j}$, the overall quality of the warranty policy for client $b_{j}$ can be define as

$$
B\left(W_{j}\right)=\sum_{i=1}^{k} \mu_{i j}^{j} B\left(W_{i j}\right) .
$$

Similarly, the quality of the warranty policy (for this group of buyers) is evaluated as follows

$$
B(W)=\sum_{j=1}^{J} \sum_{i=1}^{k} \mu_{i j}^{a} B\left(W_{i j}\right) .
$$

We assess the quality of warranty policies by comparing their balanced warranty parameters. From client's viewpoint, the warranty strategy with the largest balanced warranty parameter is the one with the highest quality. For further details see Christozov, Chukova, and Mateev (2010). 


\section{Risk of Misinforming: Static Measures}

Measuring the risk of making a wrong purchase decision at the time of the purchase is addressed by Christozov, Chukova, and Mateev (2008, 2009a). Here we will call this risk and its measures "static" to distinguish from the risk of making a wrong decision, and its measures during the adoption process we will call "dynamic".

There are two possible outcomes for the buyer's purchase decision regarding any product $\boldsymbol{D}$. It could be "YES" (positive, i.e., go ahead and purchase the product) or "NO" (negative, do not purchase the product). The client $b_{j}$ will make a positive decision if for all $a_{i j} \in A_{j}$, such that $n_{i j}>0$ and $q_{i j}>0$, the inequality $\hat{p}_{i j} \geq q_{i j}$ holds and the decision will be negative if the opposite inequality $\hat{p}_{i j}<q_{i j}$ is valid for at least one task. In addition, the correctness of this decision depends also on the relationship between $p_{i}$, the actual ability of $\boldsymbol{D}$ to solve for $a_{i j}$ and $\hat{p}_{i j}$ - the estimated ability of $\boldsymbol{D}$ to solve for $a_{i j}$. Each of the six possible orderings between $p_{i}, \hat{p}_{i j}$ and $q_{i j}$ identify whether buyer's decision to buy the product is wrong or correct with respect to task $a_{i j}$. The following notation is used to indicate the correctness/incorrectness of the buyer's purchase decision with respect to task $a_{i j}$ :

$$
r_{i j}= \begin{cases}1 & \text { the decision is } \text { wrong } \\ 0 & \text { the decision is correct }\end{cases}
$$

The following six cases are considered:

1. $p_{i}<\hat{p}_{i j}<q_{i j}$ - the product is not suitable to solve for task $a_{i j}$, the buyer's estimation of the suitability of the product is optimistic, i.e., $p_{i<} \hat{p}_{i j}$, and below the degree of acceptance, thus the decision is negative and correct and $r_{i j}=0$;

2. $p_{i}<q_{i j}<\hat{p}_{i j}$ - the product is not suitable to solve for task $a_{i j}$, the buyer's estimation of the suitability of the product is optimistic and above the threshold of acceptance, thus the decision is positive and wrong, and $r_{i j}=1$;

3. $q_{i j}<p_{i}<\hat{p}_{i j}$ - the product is suitable to solve for task $a_{i j}$, the buyer's estimation of the suitability of the product is optimistic and above the threshold of acceptance, thus the decision is positive and correct, and $r_{i j}=0$;

4. $\hat{p}_{i j}<p_{i}<q_{i j}$ - the product is not suitable to solve for task $a_{i j}$, the buyer's estimation of the suitability of the product is pessimistic, i.e., $\hat{p}_{i j}$ is less than $p_{i}$, and below the threshold of acceptance, thus the decision is again negative and correct, and $r_{i j}=0$;

5. $\hat{p}_{i j}<q_{i j}<p_{i}$ - the product is suitable to solve for task $a_{i j}$, the buyer's estimation of the suitability of the product is pessimistic and below the threshold of acceptance, thus the decision is negative and wrong, and $r_{i j}=1$;

6. $\quad q_{i j}<\hat{p}_{i j}<p_{i}$ - the product is suitable to solve for task $a_{i j}$, the buyer's estimation of the suitability of the product is pessimistic and above the threshold of acceptance, thus the decision is positive and correct, and $r_{i j}=0$.

The distance between $p_{i}$ and $\hat{p}_{i j}$ allows to define three categories of customers - optimists, pessimists and realists, according to the degree and direction of message misinterpretation. The 
amount of misinforming is measured by the distance between $p_{i}$ and $\hat{p}_{i j}$, i.e., the degree of information asymmetry of task $a_{i j}$, and it is denoted by $i a_{i j}=a b s\left(p_{i}-\hat{p}_{i j}\right)$.

\section{Risk of Misinforming: Dynamic Measures}

\section{The Nature of Dynamic Measures}

Here we propose dynamic measures of the risk of misinforming over the product warranty periods $t^{R}$ and $t^{I}$, in particular, its dependence on the coverage of the misinforming risk. This period de facto provides risk-free learning opportunities in respect to both: product's properties $\hat{p}_{i j}$ and customer's level of acceptance $q_{i j}$. We assume that the degree of relative importance of the warranty of misinforming $\mu_{i j}$ for client $b_{j}$ with respect to task $a_{i j}$ is known. Dynamic measures are justified by the fact that while using the product the client accumulates knowledge on the features and suitability of the product to solve for her tasks, i.e.,

$$
\hat{p}_{i j}=\hat{p}_{i j}(t) \underset{t \rightarrow \infty}{\longrightarrow} p_{i} \text {. }
$$

In Christozov, Chukova, and Mateev (2010) we focus on the knowledge accumulation process by introducing the measure of the quality of warranty policy, which depends on $t^{R}$ and $t^{I}$. Here, we refine the time dependency of the risk of misinforming by looking at the client's learning process related to her needs. By using the product, the client learns not only whether the product is suitable for her initial needs, but is able to identify new needs that could be addressed by this category of products. Obviously, this time dependent learning could affect the levels of product acceptance $q_{i j}$, i.e., $q_{i j}=q_{i j}(t)$ as well.

The third parameter that characterizes the client $b_{j}$ is her set of tasks and the needs $n_{i j}$ to solve them. We assume that this parameter will not change during the trial period and therefore will not influence the dynamics of the misinforming risk $n_{i j}(t)=n_{i j}$.

Figures 1 and 2 illustrate the relationship of the two learning curves: learning about the product's property - how $\hat{p}_{i j}(t)$ changes over time - and learning regarding $q_{i j}(t)$ for the two categories of clients - optimists and pessimists. The optimists overestimate the product quality; that is why the learning curve $\hat{p}_{i j}(t)$ decreases in time. The pessimists initially underestimate the product quality; therefore for them the curve $\hat{p}_{i j}(t)$ is increasing. For pessimists the two curves may intersect if the learning regarding $\hat{p}_{i j}(t)$ decreases slower in time than the learning regarding $q_{i j}(t)$. Here, we consider only the cases when the level of acceptance $q_{i j}(t)$ increases in time. In case the buyer is a pessimist and the level of acceptance decreases with learning, the two learning curves will not intersect and the misinforming warranty coverage doesn't play any role. In the optimist case and decreasing level of acceptance the situation is similar, but symmetrical, with the case of pessimists and increasing level of acceptance the two curves may intersect if the learning regarding $\hat{p}_{i j}(t)$ decreases faster than the learning regarding $q_{i j}(t)$. 


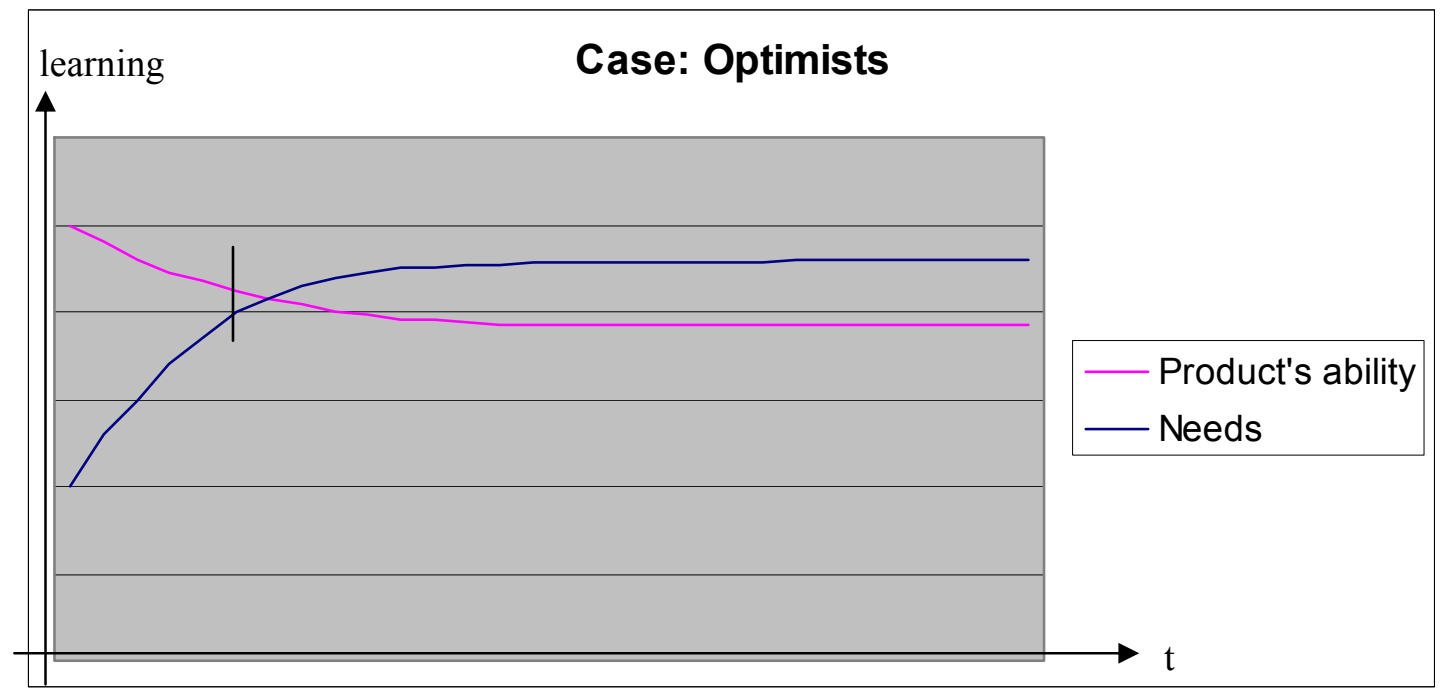

Figure 1. Dynamics of learning in case of optimist customers

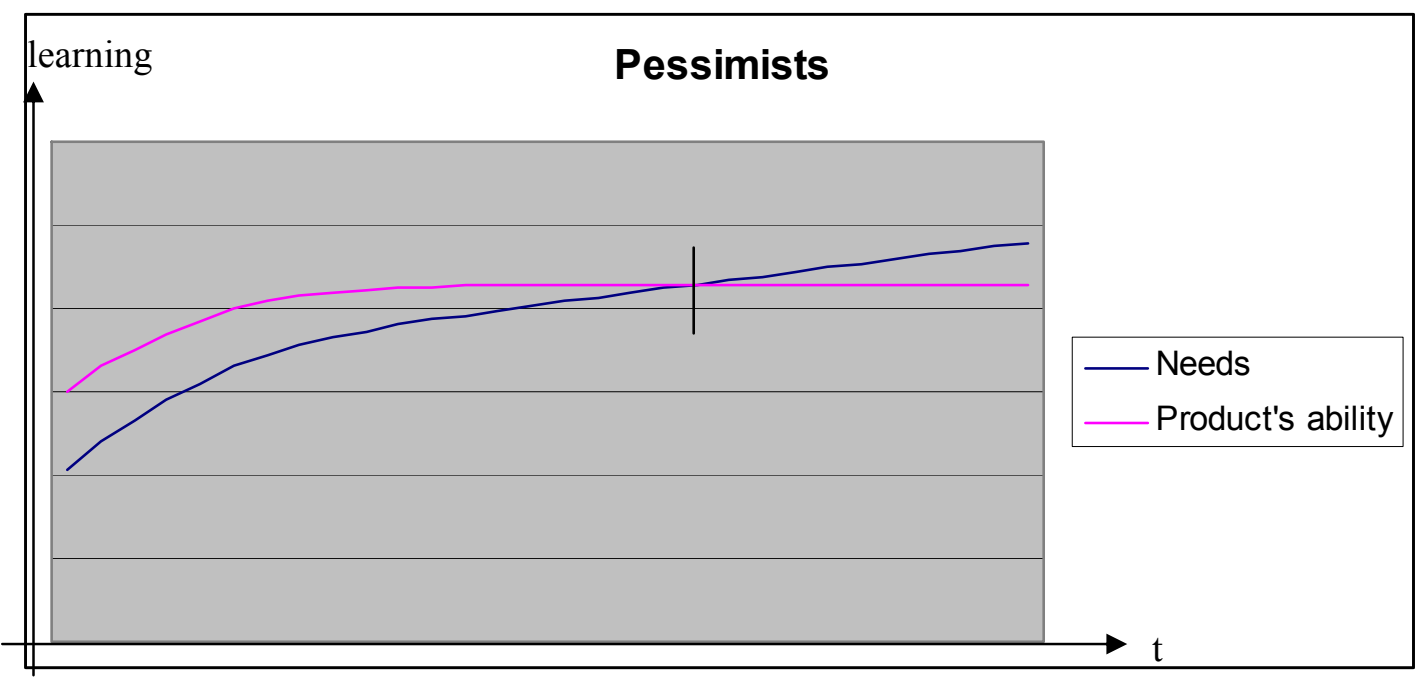

Figure 2. Dynamics of learning in case of pessimist customers

If the two learning curves intersect, which means that the product's quality becomes under the level of acceptance, the customer will realize that she has made a wrong purchase decision regarding the product. Therefore, customer's satisfaction depends on the coverage provided by the warranty of misinforming and the warranty periods play significant role in quantifying the risk of misinforming $r_{i j}(t)=r_{i j}\left(p_{i}, \hat{p}_{i j}(t), q_{i j}(t) \mid t \leq t^{I}\right)$.

To illustrate the above ideas and the proposed measures, we provide an example on how to evaluate the risks $r_{i j}(t)$. Let us assume that the product is a personal computer, and the client $b_{j}$ evaluates its performance using the response time, i.e., the PC response time is the main parameter of interest. This parameter depends on several factors such as the speed of the processor, the PC architecture and the speed of the bus, the access time of the hard disk, etc. Also, the response time depends on the particular application in use. For example, the response time of a computational task is mostly influenced by the CPU speed, and not much by the hard disk access time. A data- 
base related task is just the opposite - the hard disk access time is what influences mostly the PC performance/response time. Therefore, the actual response time of a PC is a user specific parameter. Usually, the seller provides information on the technical parameters of the product, but not the subjective, user related performance parameters. It is well known that in the process of using the product, the user learns whether the PC performance meets her specific needs. Also, during this learning period, the user might face the need to solve larger scale problems than initially intended. This additional requirement will affect (increase) the level of needed performance compared to that initially expected.

\section{Dynamic Generalization of Measures of the Risk}

Further we will present how the dynamic measures will influence the overall risks associated with the "informing process" by following the three levels in modelling this risk as presented in Christozov, Chukova, and Mateev (2009a) and generalized for the group of clients.

\section{"One-to-one" informing process: The risk of a client}

Following Christozov, Chukova, and Mateev (2009b), we will define several models to evaluate the overall risk regarding all tasks $a_{i j}$ a client $b_{j}$ is exposed to by making a decision based on received information regarding the features of the product $\mathrm{D}$ and according to her understanding of this information. We assume that the difference in these models is associated with different information components available in evaluation of the risk: the needs $n_{i j}$, the risk of a wrong decision regarding a given task $-r_{i j}$, and the degree of information asymmetry - $i a_{i j}$. Including different components, according to what data is available, we may construct the following three measures:

- A simple model - only data regarding the probability of wrong decisions $r_{i j}$ is used. It is not difficult to collect such data in commercial activities; one has to count only the claims of the unsatisfied clients:

$$
r_{j}^{s}(t)=\frac{\sum_{i=1}^{k} r_{i j}(t)\left(\mu_{i j} t^{I}+\left(1-\mu_{i j}\right) t^{R}\right)}{\sum_{i=1}^{k} \mu_{i j} t^{I}+\left(1-\mu_{i j}\right) t^{R}}
$$

If all decisions are wrong and corresponding degrees of misinforming importance $\mu_{i j}$ are equal to 1 , then, as expected, $r_{j}^{s}=1$.

- Model accounting for the client's needs. We assume that if a client $b_{j}$ doesn't need to solve tasks from given category $A_{i}^{*}$ then $n_{i j}=0$ she doesn't need to know and interpret the message regarding these tasks. In general, it is easy to see that there is a simple relationship between the level of needs and the risk of misinforming, i.e., the higher the need of a client to solve for a given task is, the higher corresponding risk of misinforming is:

$$
r_{j}^{n}(t)=\frac{\sum_{i=1}^{k} n_{i j}(t) r_{i j}(t)\left(\mu_{i j} t^{I}+\left(1-\mu_{i j}\right) t^{R}\right)}{\sum_{i=1}^{k} n_{i j}(t)\left(\mu_{i j} t^{I}+\left(1-\mu_{i j}\right) t^{R}\right)} .
$$


- Model accounting for the needs and for the degree of information asymmetry. In this model, we collect and use feedback data on the third component, the degree of error in understanding the message. The measure of the risk in this case is the most complex, but the most precise:

$$
r_{j}^{a}(t)=\frac{\sum_{i=1}^{k} n_{i j}(t) r_{i j}(t) i a_{i j}\left(\mu_{i j} t^{I}+\left(1-\mu_{i j}\right) t^{R}\right)}{\sum_{i=1}^{k} n_{i j}(t)\left(\mu_{i j} t^{I}+\left(1-\mu_{i j}\right) t^{R}\right)}
$$

\section{“One-to-Many" informing process}

In defining these risks from the seller's viewpoint we generalize the above formula for a whole group of clients. This risk is a measure of the informing quality of the message that is sent out to clients. It measures the quality of the message, i.e., how the content or meaning the sender intends to convey to the clients is described and presented in the message. In this case, we also consider three models accounting for the three information components:

- A simple model:

$$
R^{s}(t)=\frac{\sum_{j=1}^{J} \sum_{i=1}^{k} r_{i j}(t)\left(\mu_{i j}^{a} t^{I}+\left(1-\mu_{i j}^{a}\right) t^{R}\right)}{\sum_{j=1}^{J} \sum_{i=1}^{k}\left(\mu_{i j}^{a} t^{I}+\left(1-\mu_{i j}^{a}\right) t^{R}\right)}
$$

- A model accounting for the clients' needs:

$$
R^{n}(t)=\frac{\sum_{j=1}^{J} \sum_{i=1}^{k} r_{i j}(t) n_{i j}(t)\left(\mu_{i j}^{a} t^{I}+\left(1-\mu_{i j}^{a}\right) t^{R}\right)}{\sum_{j=1}^{J} \sum_{i=1}^{k} n_{i j}(t)\left(\mu_{i j}^{a} t^{I}+\left(1-\mu_{i j}^{a}\right) t^{R}\right)}
$$

- A model accounting for the needs and degree of information asymmetry:

$$
R^{a}(t)=\frac{\sum_{j=1}^{J} \sum_{i=1}^{k} r_{i j}(t) n_{i j}(t) i a_{i j}\left(\mu_{i j}^{a} t^{I}+\left(1-\mu_{i j}^{a}\right) t^{R}\right)}{\sum_{j=1}^{J} \sum_{i=1}^{k} n_{i j}(t)\left(\mu_{i j}^{a} t^{I}+\left(1-\mu_{i j}^{a}\right) t^{R}\right)}
$$

\section{An Illustrative Example}

Next, in Table 1, we illustrate the dynamics of the risk of misinforming on a PC case with a fixed period of $t^{R}=1$ year of warranty of malfunctioning and four different misinforming warranty periods, such as $t^{I}=\{0$ months, 3 months, 6 months, 9 months $\}$.

Let $\hat{p}_{j}(t)=\min \left(\hat{p}_{i j}(t)\right)$ is the expected product performance for all tasks for client $b_{j}$ and $q_{j}(t)=\max \left(q_{i j}(t)\right)$ is the threshold of the level of acceptance for the same client. 
Initially, at the time of the purchase, $t=t_{0}=0, \hat{p}_{j}\left(t_{0}\right)=1.0$. This is so, because at that time, the client believes that the product is suitable for all of his tasks, i.e., $\hat{p}_{i j}\left(t_{0}\right)=1$, for $i=1, \ldots ., k$, and $\hat{p}_{j}\left(t_{0}\right)=\min \left(\hat{p}_{i j}\left(t_{0}\right)\right)=1$. Let us assume that for the set of tasks of client $b_{j}$, the actual performance of this $\mathrm{PC}$ is $p_{j}=0.7<p_{j}\left(t_{0}\right)$, or $b_{j}$ is an optimist. Also, assume that for client $b_{j}$ the level of acceptance for her initial need for the PC performance is $q_{j}\left(t_{0}\right)=0.75$ and 5 months are needed to fully understand the capability of the product. Let us assume that the learning curve for the actually needed performance follows an increasing function. The dynamics of these data is presented in Table 1 .

Table 1. Dissatisfaction risks in a learning process

\begin{tabular}{|l|l|l|l|l|l|l|}
\hline Time (months) & $\hat{p}_{j}(t)$ & $q_{j}(t)$ & $\begin{array}{l}\text { Risk when } \\
t^{I}=0\end{array}$ & $\begin{array}{l}\text { Risk when } \\
t^{I}=3\end{array}$ & $\begin{array}{l}\text { Risk when } \\
t^{I}=6\end{array}$ & $\begin{array}{l}\text { Risk when } \\
t^{I}=12\end{array}$ \\
\hline 0 & 1.00 & 0.750 & 0 & 0 & 0 & 0 \\
\hline 1 & 0.90 & 0.770 & 0 & 0 & 0 & 0 \\
\hline 2 & 0.82 & 0.780 & 0 & 0 & 0 & 0 \\
\hline 3 & 0.75 & 0.785 & 1 & $\mathbf{0}$ & $\mathbf{0} *$ & $\mathbf{0}$ \\
\hline 4 & 0.72 & 0.790 & 1 & 1 & $\mathbf{0} *$ & $\mathbf{0}$ \\
\hline 5 & 0.70 & 0.800 & 1 & 1 & $\mathbf{0} *$ & $\mathbf{0}$ \\
\hline 6 & 0.70 & 0.805 & 1 & 1 & $\mathbf{0} *$ & $\mathbf{0}$ \\
\hline 7 & 0.70 & 0.810 & 1 & 1 & 1 & $\mathbf{0}$ \\
\hline 8 & 0.70 & 0.813 & 1 & 1 & 1 & $\mathbf{0}$ \\
\hline 9 & 0.70 & 0.815 & 1 & 1 & 1 & $\mathbf{0}$ \\
\hline
\end{tabular}

* The dissatisfaction risk is zero, because the client is protected by the warranty of misinforming and can return the product for full reimbursement.

To illustrate the behaviour of risks of misinforming over the time, we will make an additional assumption that for $b_{j}$ the ratio of importance of the two warranties is set to $\mu=0.3$. Also, for simplicity, we assume that the group of tasks is composed by only one task. Under these settings, the risks for $b_{j}$ are shown in Table 2 . 
Table 2. Dynamics of misinforming risk as a function of time and warranty coverage.

\begin{tabular}{|c|c|c|c|c|c|c|c|c|}
\hline \multirow{3}{*}{$\begin{array}{l}\text { Time } \\
t\end{array}$} & \multicolumn{4}{|c|}{$r_{i j}$} & \multicolumn{4}{|c|}{$r_{j}^{s}(t)=\frac{\sum_{i=1}^{k} r_{i j}(t)\left(\mu_{i j} t^{I}+\left(1-\mu_{i j}\right) t^{R}\right.}{\sum_{i=1}^{k} \mu_{i j} t^{t}+\left(1-\mu_{i j}\right) t^{R}}$} \\
\hline & & & & & \multicolumn{4}{|l|}{$t^{I}$} \\
\hline & 0 & 3 & 6 & 9 & 0 & 3 & 6 & 9 \\
\hline 0 & 0 & 0 & 0 & 0 & 1.00 & 0.44 & 0.28 & 0.21 \\
\hline 1 & 0 & 0 & 0 & 0 & 1.00 & 0.44 & 0.28 & 0.21 \\
\hline 2 & 0 & 0 & 0 & 0 & 1.00 & 0.44 & 0.28 & 0.21 \\
\hline 3 & 1 & $\overline{0}$ & $\overline{0}$ & $\overline{0}$ & 1.00 & 0.44 & 0.28 & 0.21 \\
\hline 4 & 1 & 1 & $\mathbf{0}$ & $\mathbf{0}$ & 1.00 & 1.00 & 0.28 & 0.21 \\
\hline 5 & 1 & 1 & $\mathbf{0}$ & $\overline{\mathbf{0}}$ & 1.00 & 1.00 & 0.28 & 0.21 \\
\hline 6 & 1 & 1 & $\mathbf{0}$ & $\mathbf{0}$ & 1.00 & 1.00 & 0.28 & 0.21 \\
\hline 7 & 1 & 1 & 1 & $\overline{0}$ & 1.00 & 1.00 & 1.00 & 0.21 \\
\hline 8 & 1 & 1 & 1 & 0 & 1.00 & 1.00 & 1.00 & 0.21 \\
\hline 9 & 1 & 1 & 1 & $\overline{\mathbf{0}}$ & 1.00 & 1.00 & 1.00 & 0.21 \\
\hline
\end{tabular}

The values of the other two risk measures are obtained by multiplying the values in Table 2 by the needs or by the needs and coefficient of information asymmetry.

\section{Conclusion}

In this paper we proposed an approach to quantify the dynamics of risk of misinforming over the learning period during the adoption of a new product. The proposed measures may help in better understanding the process of adoption with respect of buyer's satisfaction and the risks associated with dissatisfaction. The misinforming warranty coverage is considered as a tool to encourage learning and to facilitate adoption by reducing the risk of uncertainty and potential dissatisfaction.

This paper is our first attempt to address the dynamics in the purchase and adoption processes. Further incorporation of these ideas into measuring the quality of warranty policies will provide a better insight on the seller/buyer relationship and on instruments used to facilitate and support successful communication between them. Another open issue is how to collect data regarding the learning evolution in the adoption process of a new product.

Our next task will be to design an experiment for collecting appropriate data, which will allow for better illustration of our new models. Also, we will focus on modelling the dynamic measures of the risk of misinforming in the context of competing products. 


\section{References}

Christozov, D., Chukova, S., \& Mateev, P. (2007). On the relationship between warranty and the risk of information asymmetry. Journal of Issues in Informing Science and Information Technology, 4, 235 249. Retrieved from http://proceedings.informingscience.org/InSITE2007/IISITv4p235249Chri295.pdf

Christozov, D., Chukova, S., \& Mateev, P. (2008). Warranty and the risk of misinforming: Evaluation of the degree of acceptance. Journal of Issues in Informing Science and Information Technology, 5, 667677. Retrieved from http://proceedings.informingscience.org/InSITE2008/IISITv5p667677Chris444.pdf

Christozov, D., Chukova, S., \& Mateev, P. (2009a). On two types of warranties: Warranty of malfunctioning and warranty of misinforming. Asia-Pacific Journal on Operation Research, 26(3), 399-420.

Christozov, D., Chukova, S., \& Mateev, P. (2009b). Chapter 11. Informing processes, risks, evaluation of the risk of misinforming. In T. G. Gill \& E. Cohen (Eds.), Foundations of informing science: 19992008 (pp. 323-356). Santa Rosa, CA: Informing Science Press.

Christozov, D., Chukova, S., \& Mateev, P. (2009c). The risk of misinforming for competing messages. Journal of Issues in Informing Science and Information Technology, 6, 351-364. Retrieved from http://iisit.org/Vol6/IISITv6p351-364Christozov627.pdf

Christozov, D., Chukova, S., \& Mateev, P. (2010). Assessment of quality of warranty policy. Interdisciplinary Journal of Information, Knowledge, and Management, 5, 61-72. Retrieved from http://ijikm.org/Volume5/IJIKMv5p061-072Christozov447.pdf

Appendix. Notations and Definitions

\begin{tabular}{|c|c|}
\hline Notation & Definition \\
\hline$D$ & the product \\
\hline$B=\left\{b_{j}\right\}, j=1,2, \ldots, n$ & the set of buyers \\
\hline$A_{j}=\left\{a_{i j}\right\}, i=1,2, \ldots, k_{j}$ & tasks, which the $b_{j}$ needs to solve by using the product \\
\hline$A=\bigcup_{j=1}^{n} A_{j}$ & set of tasks of all buyers \\
\hline$A_{i}^{*}, i=1,2, \ldots, k$ & categories of tasks \\
\hline$n_{i j}$ & the need of $b_{j}$ to solve her task $a_{i j .} 0 \leq n_{i j} \leq 1$ \\
\hline$q_{i j}$ & $\begin{array}{l}\text { degree of acceptance. The minimal quality (a thresh- } \\
\text { old), which the product must possess in order to meet } \\
\text { the customer } b_{j} \text { expectations regarding her task } a_{i j} \text {. }\end{array}$ \\
\hline$p_{i}=p\left(A_{i}^{*}\right)$ & $\begin{array}{l}\text { probability that the product will solve problems from } \\
\text { category } A_{i}^{*} . \text { Or the level to which the product } D \text { may } \\
\text { satisfy the buyers needs regarding the tasks from this } \\
\text { category }\end{array}$ \\
\hline$\hat{p}_{i j}=\hat{p}\left(a_{i j}\right)$ & $\begin{array}{l}\text { subjective assessment of the buyer } b_{j} \text { regarding the } \\
\text { probability (level of satisfaction) that the product will } \\
\text { be suitable for solving her task } a_{i j}\end{array}$ \\
\hline
\end{tabular}




\begin{tabular}{|c|c|}
\hline Notation & Definition \\
\hline$r_{i j}$ & $\begin{array}{l}\text { indicator of the decision correctness } r_{i j}=0 \text { if the decison } \\
\text { is correct; } r_{i j}=1 \text { means wrong decision }\end{array}$ \\
\hline$i a_{i j}=a b s\left(p_{i}-\hat{p}_{i j}\right)$ & measure of information asymmetry \\
\hline$W_{p}(t)$ & warranty policy. $t$ - time of the coverage \\
\hline$W_{R}\left(t^{R}\right)$ & $\begin{array}{l}\text { warranty policy regarding risk of malfunctioning (risk } \\
\text { of low reliability) }\end{array}$ \\
\hline$W_{I}\left(t^{I}\right)$ & warranty policy regarding the risk of misinforming \\
\hline$W_{p}=\left\{t^{R}, t^{I}\right\}$ & mixed warranty policy, if $t^{R} \neq 0$ and $t^{I} \neq 0$ \\
\hline$W_{p}\left(t^{R}, 0\right)$ or $W_{p}\left(0, t^{I}\right)$ & pure warranty policies \\
\hline$\mu_{i j}, 0 \leq \mu_{i j} \leq 1$ & $\begin{array}{l}\text { subjective assessment of importance of the misinform- } \\
\text { ing warranty policy for making purchase decision by } b_{j} \\
\text { in respect to task } a_{i j} \text {. }\end{array}$ \\
\hline$B\left(W_{i j}\right)=\mu_{i j} t^{I}+\left(1-\mu_{i j}\right) t^{R}$ & $\begin{array}{l}\text { "balanced" value - represents the effective coverage of } \\
\text { a warranty policy }\end{array}$ \\
\hline$Q\left(W_{i j}\right)=\sqrt{\left(t^{I}-B\left(W_{i j}\right)\right)^{2} \mu_{i j}+\left(t^{R}-B\left(W_{i j}\right)\right)^{2} \cdot\left(1-\mu_{i j}\right)}$ & $\begin{array}{l}\text { standard deviation - represents the uncertainty associ- } \\
\text { ated with the warranty policy }\end{array}$ \\
\hline$r_{j}^{s}\left(r_{i j}\right)$ & $\begin{array}{l}\text { "simple" measure of the risk in a purchase decision for } \\
b_{j} \text {, depends only on whether the decision is correct or } \\
\text { not }\end{array}$ \\
\hline$r_{j}^{n}\left(r_{i j}, n_{i j}\right)$ & $\begin{array}{l}\text { measure of the risk in a purchase decision for } b_{j} \text {, de- } \\
\text { pends on whether the decision is correct or not; and the } \\
\text { needs }\end{array}$ \\
\hline$r_{j}^{a}\left(r_{i j}, n_{i j}, i a_{i j}\right)$ & $\begin{array}{l}\text { measure of the risk in a purchase decision for } b_{j} \text {, which } \\
\text { incorporates the indicator for correctness of the deci- } \\
\text { sion, the needs and the measure of information asym- } \\
\text { metry }\end{array}$ \\
\hline$R_{j}^{s}\left(r_{i j}\right)$ & $\begin{array}{l}\text { "simple" measure of the risk in a purchase decision for } \\
\text { group } B \text {, depends only on whether the decision is cor- } \\
\text { rect or not }\end{array}$ \\
\hline$R_{j}^{n}\left(r_{i j}, n_{i j}\right)$ & $\begin{array}{l}\text { Measure of the risk in a purchase decision for group } B \text {, } \\
\text { depends on whether the decision is correct or not; and } \\
\text { the needs }\end{array}$ \\
\hline$R_{j}^{a}\left(r_{i j}, n_{i j}, i a_{i j}\right)$ & $\begin{array}{l}\text { measure of the risk in a purchase decision for group } B \text {, } \\
\text { which incorporates the indicator for correctness of the } \\
\text { decision, the needs and the measure of information } \\
\text { asymmetry }\end{array}$ \\
\hline$r(t)$ and $R(t)$ & dynamic measures of the risk for $b_{j}$ and for group $B$ \\
\hline
\end{tabular}




\section{Biographies}

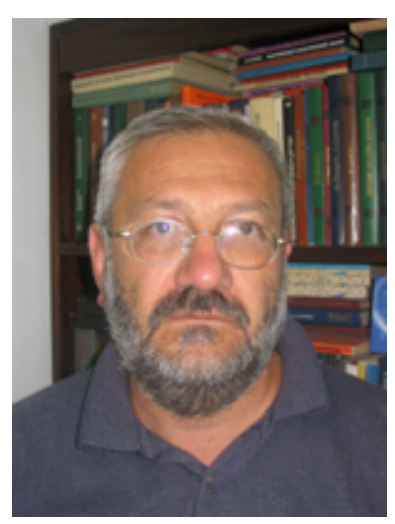

Dimitar Christozov is a Professor of Computer Science at the American University in Bulgaria, Blagoevgrad 2700, Bulgaria since 1993, email: dgc@aubg.bg. He has more than 30 years of experience in areas as computer science, quality management and information systems. He graduated Mathematics from Sofia University "St. Kliment Ohridski" in 1979. He completed his $\mathrm{PhD}$ thesis "Computer Aided Evaluation of Machine Reliability" in 1986. In 2009 he completes his D.Sc. thesis on "Quantitative Measures of Informing Quality". In ICTT "Informa" (1986-1993) Dr. Christozov was involved in establishing the national information network for technology transfer and research in the areas of technologies assessment, integral quality measures and information systems for quality management. In these areas he was recognized as one of the leading experts in Bulgaria. Professor Christozov has more than 70 publications as separate volume, journal papers and papers in refereed proceedings. He is a founding member of Informing Science Institute and chair of Bulgarian Informing Science Society; and member of the Bulgarian Statistical Society.

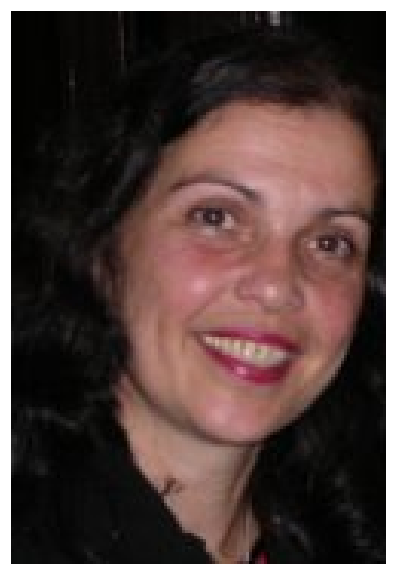

Dr. Stefanka Chukova is a Reader in Operations Research at the School of Mathematics, Statistics and Operation Research, Victoria University of Wellington, Private Bag 600, Wellington, New Zealand, e-mail: schukova@msor.vuw.ac.nz. She has a PhD and MSc in Mathematics (concentration in Probability and Statistics) and BSc in Mathematics from University of Sofia, Sofia, Bulgaria. Her research interests are in applied stochastic models, warranty analysis, reliability and queuing. She has more than 50 publications and has presented papers at national and international conferences.

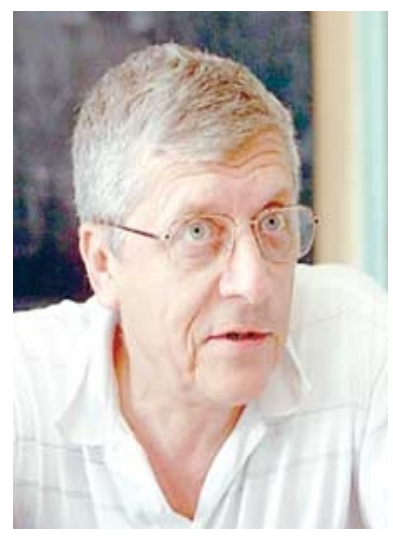

Dr. Plamen S. Mateev is Associate professor in Faculty of Mathematics and Informatics, Sofia University "St.Kliment Ohridski", Department "Probability, Operation Research, Statistics", Bulgaria, 1164 Sofia, 5, J.Boucher str., e-mail: pmat@fmi.uni-sofia.bg.

His MSc in Mathematical Statistics is from Sofia University and his $\mathrm{PhD}$ is from Moscow State University. The research interests are in communication theory, applied statistics, statistical software and applications. More than 70 papers are published in scientific journals and proceedings of scientific conferences. He was the Chair of Bulgarian Statistical Society and member of ENBIS and Bulgarian Informing Science Society. 